\title{
3D Position Mapping of ContinuUm ARM
}

\author{
Alaa Al-Ibadi \\ University of Salford \\ Computing, Science and Engineering \\ a.f.a.al-ibadi@edu.salford.ac.uk
}

\author{
Samia Nefti-Meziani \\ University of Salford \\ Computing, Science and Engineering \\ S.Nefti-Meziani@salford.ac.uk
}

\author{
Steve Davis \\ University of Salford \\ Computing, Science and Engineering \\ S.T.Davis@salford.ac.uk
}

\begin{abstract}
Modelling a continuum arm is one of the major challenges in soft robotic researches. An accurate position model allows wider use of continuum robot arms in industrial and medical applications. Furthermore, accurate control can be achieved. This paper illustrates the 3D position of a constructed soft arm from 4 pneumatic muscle actuators (PMAs) in parallel, and models the movement of its free end in space. The performance of the contraction and extension PMAs and the behaviour of the contraction and extension arms are analysed, and a comparison between the two arms is explained. Finally, the mathematical models are presented and validated.
\end{abstract}

Keywords - Contraction and Extension PMA, Continuum Arm, Experimental Model, 3D Position, Mapping.

\section{INTRODUCTION}

Many robot arms are used for industrial and medical applications. Therefore, robot-human interactions are increased [1]. The rigidity is the major specification of such arms, so the safety factor is low and the possibility of injury is significantly high.. Whilst at work, there is a risk that an accident could develop at any time due to a robot body or its moving manipulator having a fault [2].

For that reason and to reduce the risk of injury a type of soft actuator called a pneumatic muscle actuator (PMA) is used to construct a continuum arm to replace the existing rigid arm. These actuators have numerous advantages over standard pneumatic cylinders, including high power to weight ratio, low workspace requirement, flexible structure [3-8], infinite degrees of freedom (DOF) [9-11], variable installation options, no mechanical wear, low compressed-air consumption, availability of dimension, low cost and robust reliability for human use [5, 8]. Apart from these advantages, PMAs have been regarded as a suitable substitute for other actuators, such as electrical and hydraulic [4, 12]. Furthermore, the robot is expected to be safer and more flexible $[5,7,13]$.

Despite its distinct advantages, PMA exhibits highly nonlinear features $[7,8,12,14-17]$, which are time dependent.
The nonlinearity in the PMA is due to the compressibility of air, the inner tube's elastic-viscous properties and geometrically complex behaviours of the PMA outer covering $[3,5,7]$. Moreover, the hysteresis behaviour is caused by the inner tube, which produces different characteristics of PMA during contracting and expanding $[6,8,18]$. This makes the modelling and controlling of pneumatic muscles more difficult $[3-5,19,20]$.

Current models do not fully explain every stage of the mechanical performances; therefore an enhanced model is still required [5]. Different models for contraction force have been proposed to describe the behaviours of the PMAs. Among these models, the Chou and Hannaford model [21] and the Tondu and Lopez model [15] are widely used. These models are based on the assumption of the virtual effects of the cylindrical shape and the small thickness of the inner tube [3, $15,21]$. Even though there are excellent initial descriptions of the mechanical behaviours, these models are still limited in predicting the performance of the PMA, at least in no-load situations. Furthermore, the pulling force, length change, air pressure supply, radius and material properties are the major parameters of the PMA. Dynamic performances and the relationships between these parameters differ greatly from one PMA to another.

In this paper, three different lengths actuators are constructed for both the contractor and extensor PMAs. Their performances are considered and one arm is built for each type. The 3D position of the free end is studied and a mathematical model formulated to describe the position change as a function of air pressure input.

\section{StRUCTURE OF PNEUMATIC MUSCLE ACTUATOR}

The pneumatic muscle actuator (PMA), which was first developed by Joseph L. McKibben in the 1950's, is made from an inner rubber tube surrounded by a braided sleeve [21]. The McKibben artificial muscle is the most widely used, due to its simple structure. Its working principle is very simple: 
The surface stress of the inner tube is transformed into an axial contraction force [22]. The amount of this force depends on the amount of air pressure. Fig.1 illustrates the structure of the PMA, in addition to the material and parts used to build it.

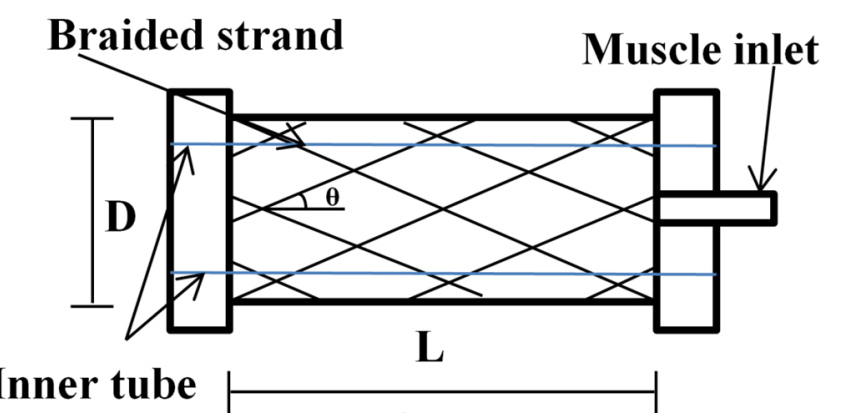

Fig.1 The structure of the pneumatic muscle actuator

L \& D represent the length and the diameter of the air muscle without air pressure and $\theta$ is the braided angle, which is the angle between the vertical line and the braided strand (b). The value of this angle varies from $0^{\circ}$ to $180^{\circ}$ based on the structure and is a major factor in muscle behaviour.

There is a similarity in behaviour between human muscle and the pneumatic muscle; they contract by thickening due to the pressure in the inner tube. The Bridgestone Company introduced it again as a rubber actuator in the late 1980s. Since then, the robots are actuated by PMAs especially for medical applications [4].

\section{OPERATION OF PMA}

Kelasidi, et al. [3] explain the operating principle of the contraction pneumatic muscle under two conditions: a) varying the input pressure at constant load, and; b) under constant pressure and changing the attached load. The diameter of the braided sleeve is maximized by increasing the air pressure whilst the length of muscle will decrease, additional air will lead to contracting the muscle and increasing in thickness [4]. Fig.2 below describes the braided sleeve operation action.

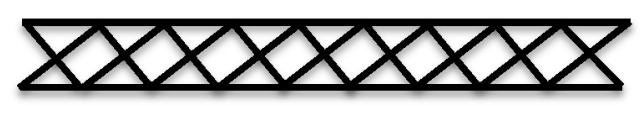

(a) Before pressurization

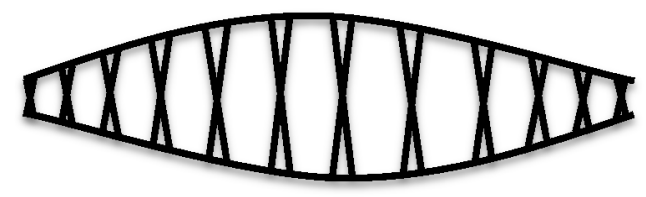

(b) After pressurization

Fig.2 The operational behaviour of the braided sleeve

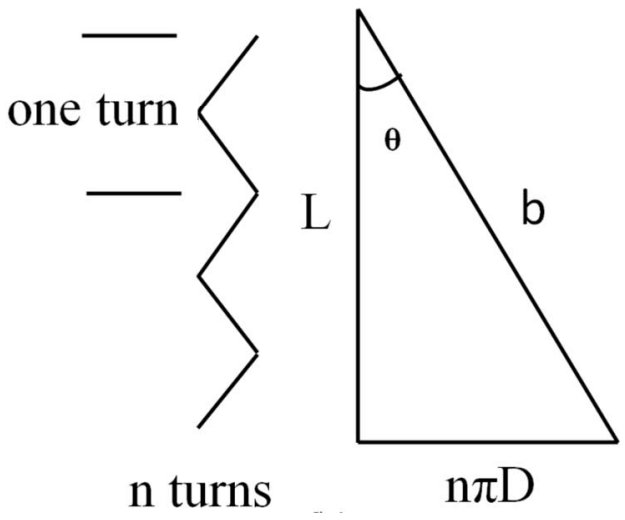

Fig.3 The parameters of the PMA

In Fig. 3, $\mathrm{n}$ is the number of strand turns from end to end of the muscle, which is constant for each muscle. The other parameters (L, D and $\theta$ ) change according to air pressure and the shape of the PMA. In the first case, as shown in Fig.4, PMA is fixed at one end and a constant load is attached to the other end. The gauge pressure gradually increases from zero bar. At a certain pressure value $\mathrm{P}_{1}$, pulling force will develop and lift the attached load until it reaches equilibrium, where the pulling force is equal to the mass weight [3].

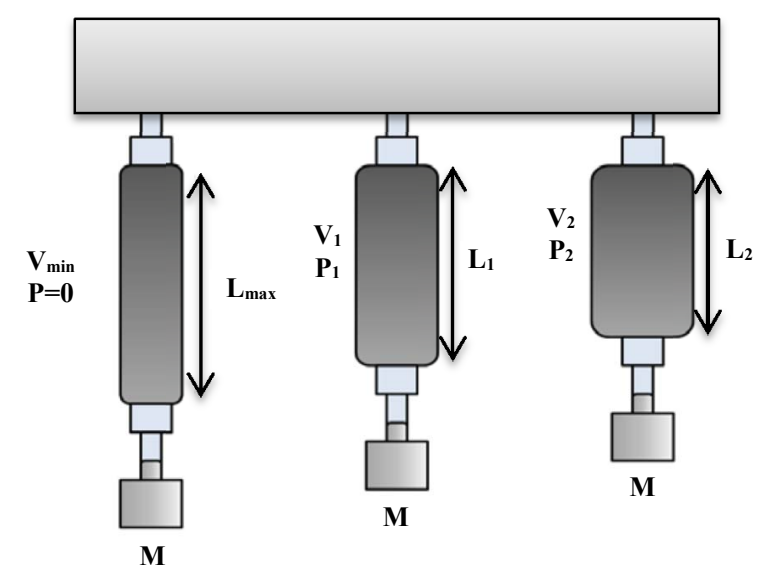

Fig.4 Constant load test of the PMA

At this point, the volume increases to $\mathrm{V}_{1}$ and the length reduces to $L_{1}$. Supplying more air to the muscle at pressure $P_{2}$ will increase the volume and make the PMA contract more to $\mathrm{L}_{2}$ until the air pressure reaches its maximum value, which depends on the construction of the PMA.

The second operation case is pressurizing the PMA at constant air pressure $\mathrm{P}$, and then a variable load is attached as shown in Fig.5. 


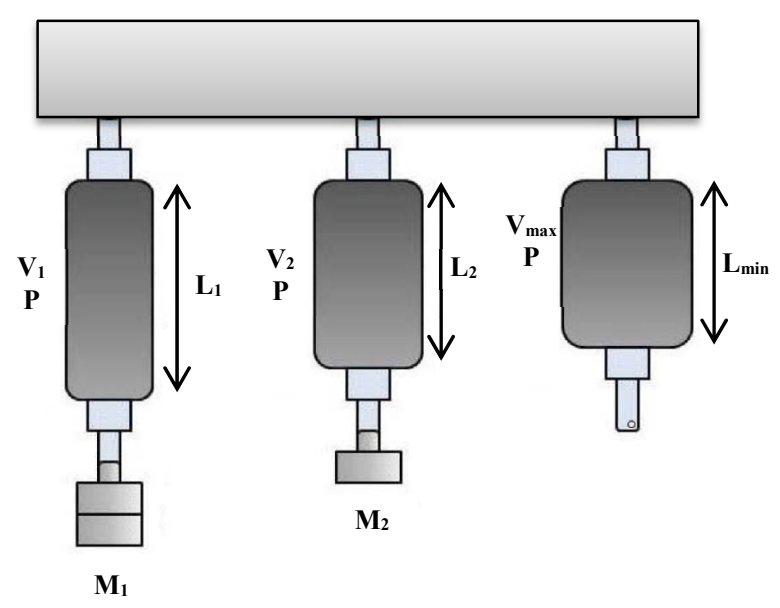

Fig.5 Constant pressure test of the PMA

Reducing the load from $\mathrm{M}_{1}$ will increase the volume and decrease the length of the muscle [3, 4, 13].

Kang, et al. [23] argue that in most applications, the PMA is used as a contraction muscle in order to establish a pulling force due to increasing the air pressure, whilst there is another common use in behaviour as an extending mode. Interest in soft robotic manipulators has significantly increased due to their ability to configure with surrounding environments, acting with a wide range of objects which are different in size. The actuators used in OctArm V (see Fig.6) are related to contractor McKibben actuators; both are operated by supplying air pressure to the rubber tubes encased in a braided sleeve. Where McKibben actuators have a braided angle $\theta<$ $54.7^{\circ}$, this resulted in them contracting due to the air pressure, the soft actuators used in the OctArm V manipulators have $\theta>$ $54.7^{\circ}$. This type of actuator is extended in length and contracted in diameter, which is caused by the air pressure [24].

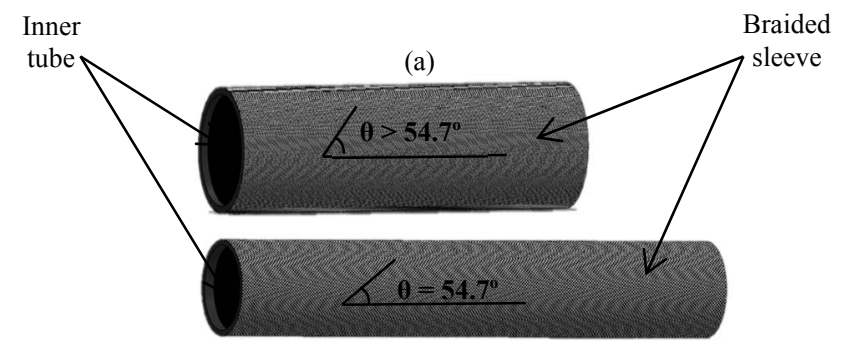

(b)

Fig.6 Extension PMA.

(a) Before pressurizing, (b) After pressurizing

\section{CONTRACTOR PNEUMATIC MUSClE ACTUATOR}

Many PMAs can be constructed in different lengths and diameters. Each actuator is made from a braided sleeve covering the rubber tube and the two ends are closed with pieces of any solid material, and left with a small hole as an air input in one end. Actuator nominal lengths between $10 \mathrm{~cm}$ and
$40 \mathrm{~cm}$ have been used by numerous researchers, including Anh [12], Chou and Hannaford [21], Tondu and Lopez [15], Wickramatunge and Leephakpreeda [5], and Ranjan, et al. [4]. In this section, $20 \mathrm{~cm}, 30 \mathrm{~cm}$ and $40 \mathrm{~cm}$ actuators are constructed with ca $1.76 \mathrm{~cm}$ diameter. Table 1 shows the used material for each actuator. These actuators are set as contractor type by choosing a braided angle $(\theta)$ of less than $54.7^{\circ}$.

Table 1 Description of material used in the contractor PMA

\begin{tabular}{|c|c|}
\hline Material & Model/Type \\
\hline Rubber tube & 700c $* 18-25$ \\
\hline Braided sleeve & RS 408-215 \\
\hline Plastic 3D printed ends & $/$ \\
\hline Air muscle kit & $/$ \\
\hline Cable tie & $/$ \\
\hline
\end{tabular}

The first experiment is made for the three PMAs. Table 2 gives the specification of the PMAs under study.

The air pressure is applied to each actuator simultaneously and regulated by a valve from $0-5$ bar in 0.5 bar steps; then it is decreased backwards to zero, to observe the hysteresis. At each value of the air pressure, the length $L$, the percentage of length change, the braided angle $\theta$, the diameter $\mathrm{D}$ and the contraction ratio $\varepsilon$ of the actuators are recorded.

Table 2 Specifications of the contractor PMAs under study

\begin{tabular}{|c|c|c|}
\hline Nominal length Lo $(\mathbf{c m})$ & Diameter D (cm) & Braided angle $\boldsymbol{\theta}$ (degree) \\
\hline 20 & 1.767 & 31.35197 \\
\hline 30 & 1.752 & 30.02661 \\
\hline 40 & 1.764 & 30.285804 \\
\hline
\end{tabular}

Where: $\varepsilon=\frac{\mathrm{L}_{0}-\mathrm{L}}{\mathrm{L}_{0}}$

Fig.7 shows the length change against air pressure for the $30 \mathrm{~cm}$ actuator.

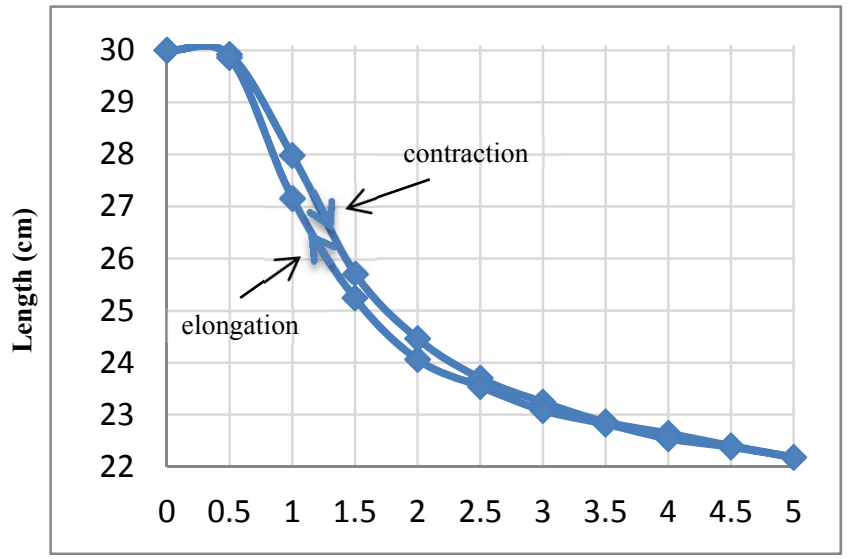

Pressure (bar)

Fig.7 Plot of actuator length change against air pressure. 
To verify the second operation for the contractor PMA, an air pressure is applied from 1.5 to 5 bar by 0.5 bar steps. At each value a load is attached to the free end of the actuator, increasing from $0 \mathrm{~kg}$ to $10 \mathrm{~kg}$ by $0.5 \mathrm{~kg}$ steps, then the length of the actuator is recorded. Fig. 8 gives the length of a $30 \mathrm{~cm}$ PMA as a function of pressure at fixed weight values.

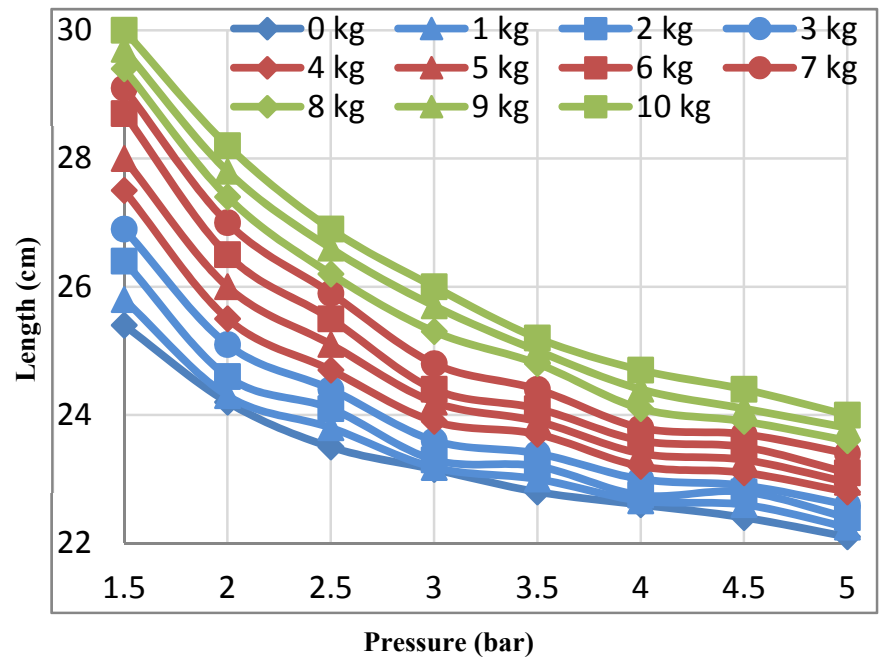

Fig.8 The length of the actuator against the pressure at fixed weight values

\section{EXTENSOR PNEUMATIC MUSCLE ACTUATOR}

A similar procedure is used to construct the extensor actuator, while the length of the braided sleeve is triple the length of the inner tube to set the braided angle more than the threshold value. Three actuators are built as shown in Table 3 .

Table 3 Specification of the extensor PMAs under study

\begin{tabular}{|c|c|c|}
\hline Nominal length $\mathbf{L}_{\mathbf{0}}(\mathbf{c m})$ & Diameter D (cm) & Braided angle $\boldsymbol{\theta}$ \\
\hline 22 & 3.0 & 70.2175 \\
\hline 32 & 3.0 & 71.5149 \\
\hline 42 & 3.0 & 72.438 \\
\hline
\end{tabular}

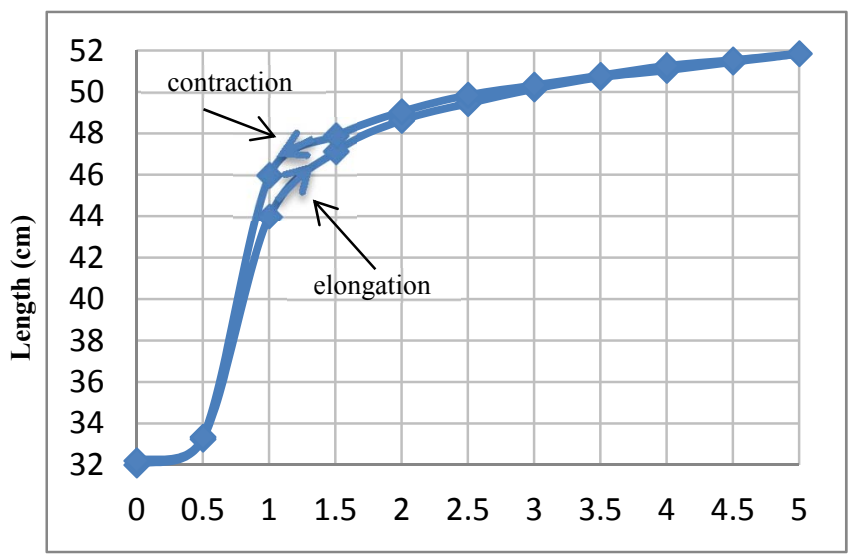

Pressure (bar)

Fig.9 Plot of actuator length change against air pressure.
Two experiments were done for these actuators; Fig.9 illustrates the length of the $32 \mathrm{~cm}$ extensor PMA as a function of air pressure and Fig. 10 gives the length of the actuators against the pressure at different load values.

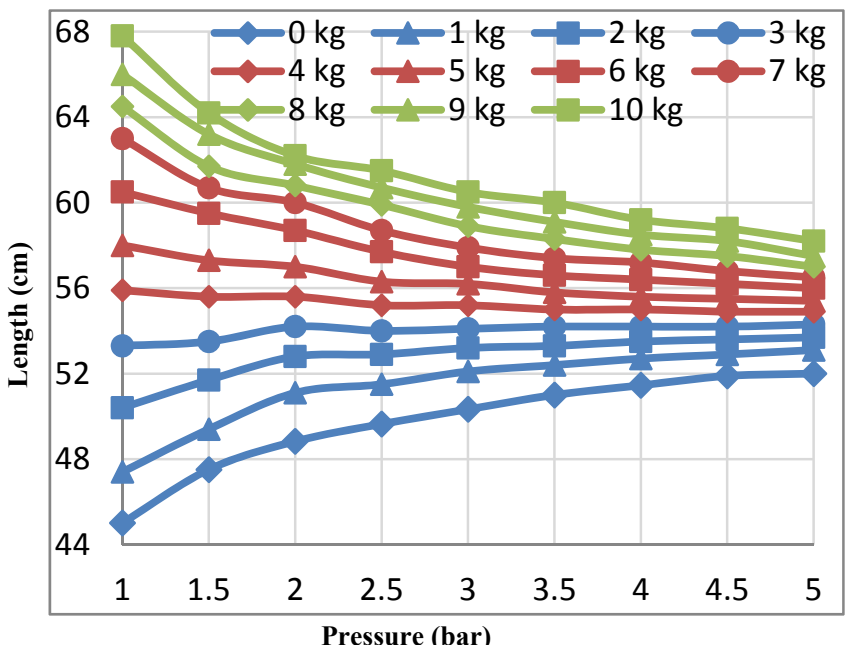

Fig.10 The length of the actuator against the pressure at fixed weight values

\section{CONTINUUM ARM}

Numerous structures could be designed as parallel PMAs. In this section, four identical $30 \mathrm{~cm}$ contractor PMAs are constructed as an arm with two ends as shown in Fig.11 and another arm is built using four $32 \mathrm{~cm}$ extensor actuators as illustrated in Fig.12. As shown in the two figures, there is one muscle in the centre of the arm, and the other three are located as a $120^{\circ}$ displacement. The distance between each muscle's centre and the centre of the arm is $30 \mathrm{~mm}$.

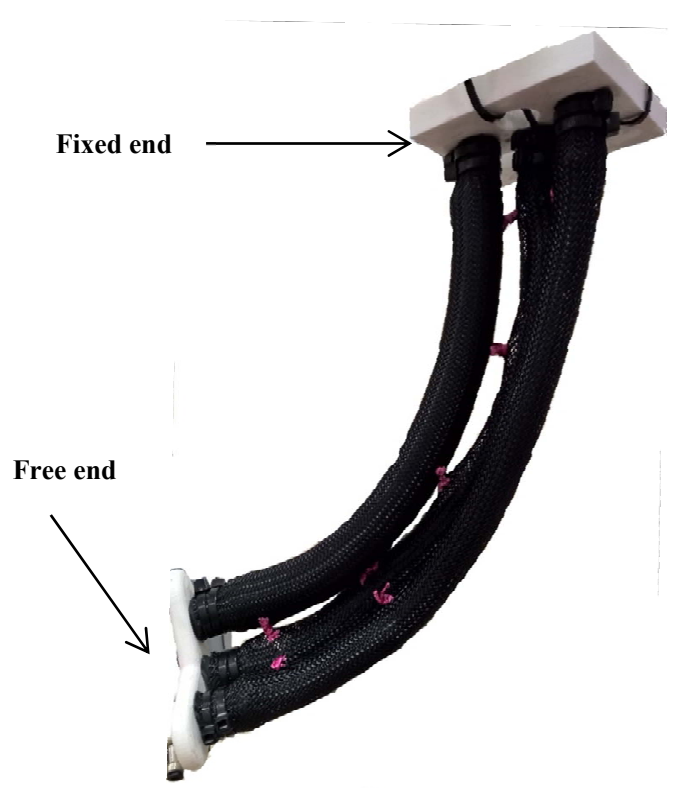

Fig.11 A contractor continuum arm at certain pressure 


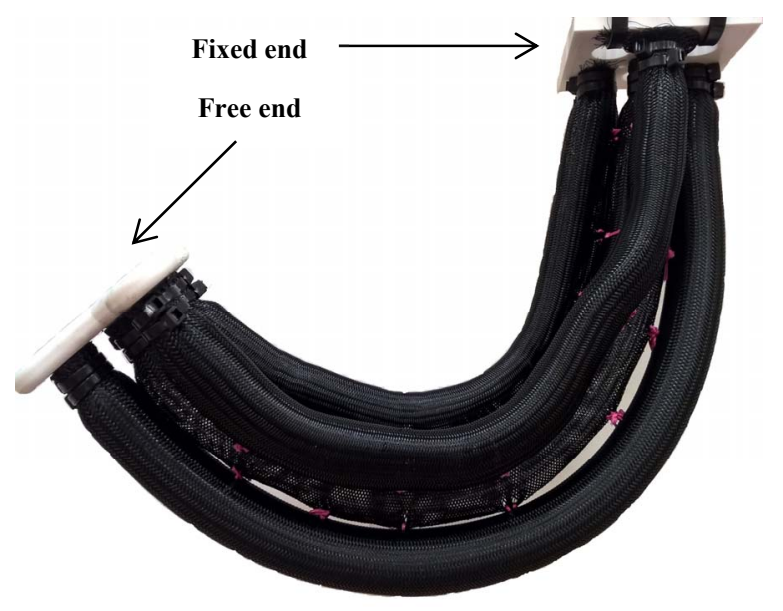

Fig.12 An extensor continuum arm at certain pressure

The pneumatic muscle actuator arm has a smooth bending behaviour when it is actuated by air [25]. A number of studies have been done on curvature $[25,26]$. In this section, one actuator in the corner is pressurized from 0-6 bar and the other three actuators are supplied by fixed amount of air pressure equal to 0.5 bar to achieve a suitable stiffness. The 3D position of the free end is observed by a $3 \mathrm{D}$ sensor attached to the arm end.

The following set of equations is formulated to model the $3 \mathrm{D}$ position points for the contractor arm.

$x_{m}=0.4939-\frac{0.496126}{1+3.3245 P^{3.6758}}$

$y_{m}=-9.49315+\frac{9.51}{1+8.375 P^{4.992}}$

$z_{m}=-20.8464+\frac{57.84636}{1+1.118 P^{3.6753}}$

The experiment points $(\mathrm{x}, \mathrm{y}, \mathrm{z})$ and the model points $\left(\mathrm{x}_{\mathrm{m}}, \mathrm{y}_{\mathrm{m}}\right.$, $\left.Z_{m}\right)$ are plotted as a function of pressure in Fig13 and Fig.14 for the contractor arm and extensor arm respectively.

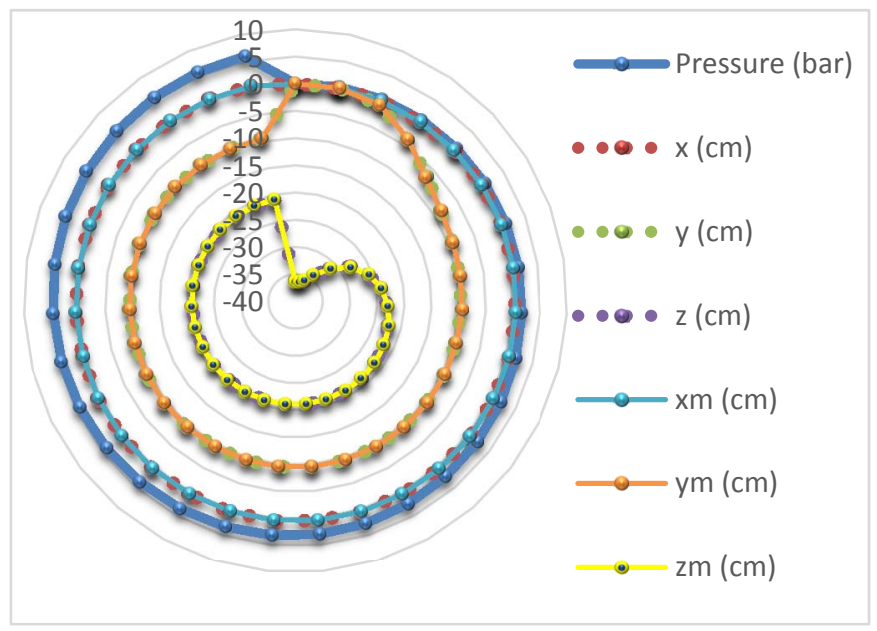

Fig.13 A 3D position mapping for the contractor Arm
A similar test is done to model the $3 \mathrm{D}$ pints for an extensor arm as follows:

$$
\begin{aligned}
& x_{m}=-26.8152 P^{7.804} \quad \text {,for } \quad 0 \leq \mathrm{P} \leq 0.8 \\
& x_{m}=4.092755-13.5786 e^{-0.53084 P} \quad \text {,for } \mathrm{P}>0.8 \\
& y_{m}=-45.505 P^{7.8467} \quad \text {,for } \quad 0 \leq \mathrm{P} \leq 0.8 \\
& y_{m}=-1.3946-8.4021 e^{-0.2513 P} \quad \text {,for } \mathrm{P}>0.8 \\
& z_{m}=-10.011-\frac{28.989}{\left(1+(1.71 P)^{5}\right)^{0.339}} \quad \text {,for } 0 \leq \mathrm{P} \leq 6
\end{aligned}
$$

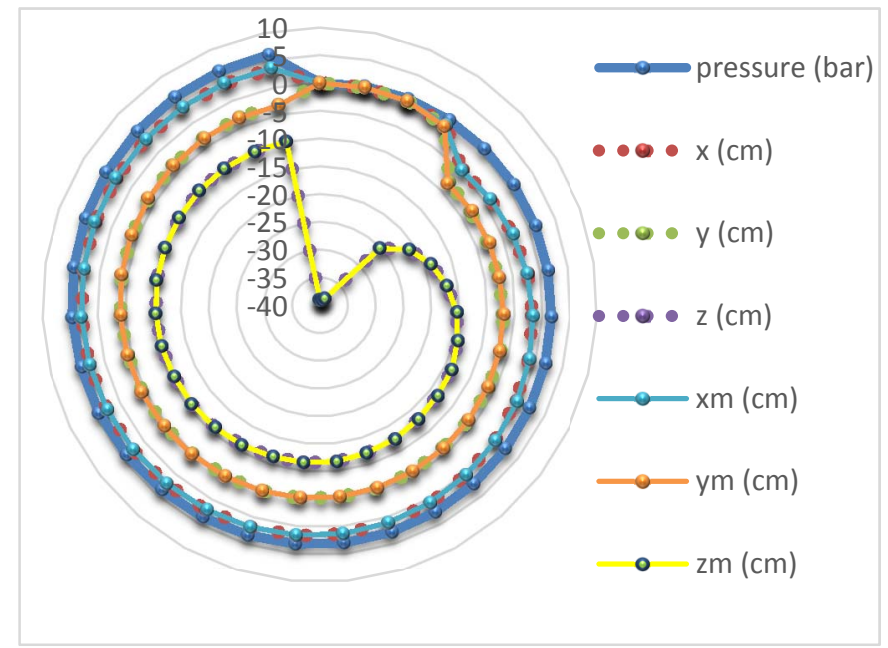

Fig.14 A 3D position mapping for the extensor Arm

The two figures illustrate significant matching between the experimental and model data. These sets of equations for both types of PMA make control of the continuum arm more efficient. Table 4 lists the mean squared error (MSE) for 3D points of both arms.

$$
M S E=\frac{1}{n} \sum_{i=1}^{n}\left(A-A_{m}\right)^{2}
$$

Where $\mathrm{A}$ is the Cartesian point and $\mathrm{A}_{\mathrm{m}}$ its model value.

Table 4 The list of mean square error for both arms

\begin{tabular}{|l|l|l|}
\hline & MSE - Contractor & MSE - Extensor \\
\hline $\mathrm{x}$ & 0.004949 & 0.006926 \\
\hline $\mathrm{y}$ & 0.009267 & 0.020926 \\
\hline $\mathrm{z}$ & 0.011981 & 0.065064 \\
\hline
\end{tabular}

\section{CONCLUSION}

Two experiments were done for the contractor and extensor PMA by changing the air pressure at no load and observing the length and by changing the load at fixed air pressure. 
These two tests illustrated the behaviour of the air muscle. One actuator was chosen from each type to build a 4-PMAs arm, and then an experiment was made to study the position points of the free end due to variation in air pressure at one actuator. These data were modelled mathematically by a set of equations and the validations explain the accuracy of this model. This mathematical model makes the position control of the continuum arm more efficient.

As a future work, a control system could be built to control the three-dimensional positions for a continuum arm of any structure.

\section{ACKNOWLEDGMENT}

The authors would like to thank the ministry of higher education/Iraq, University of Basrah, computer-engineering department for providing scholarship support to the first author of this paper

\section{REFERENCES}

[1] S. Haddadin, A. Albu-Schäffer, and G. Hirzinger, "Safety Evaluation of Physical Human-Robot Interaction via CrashTesting," in Robotics: Science and Systems, 2007, pp. 217-224.

[2] A. Bicchi and G. Tonietti, "Fast and soft arm tactics: dealing with the safety-performance tradeoff in manipulators design and control," IEEE Robotics and Automation Magazine, Special Issue on 'Safety Among Us, vol. 11, pp. 22-33, 2004.

[3] E. Kelasidi, G. Andrikopoulos, G. Nikolakopoulos, and S. Manesis, "A survey on pneumatic muscle actuators modeling," in 2011 IEEE International Symposium on Industrial Electronics (ISIE), , 2011, pp. 1263-1269.

[4] R. Ranjan, P. Upadhyay, A. Kumar, and P. Dhyani, "Theoretical and Experimental Modeling of Air Muscle," International Journal of Emerging Technology and Avanced Engineering, vol. 2, pp. 112-119, 4 Apr 2012.

[5] K. C. Wickramatunge and T. Leephakpreeda, "Study on mechanical behaviors of pneumatic artificial muscle," International Journal of Engineering Science, vol. 48, pp. 188198,2010

[6] T. Leephakpreeda, "Fuzzy logic based PWM control and neural controlled-variable estimation of pneumatic artificial muscle actuators," Expert Systems with Applications, vol. 38, pp. 78377850, 2011.

[7] P. K. Jamwal and S. Q. Xie, "Artificial Neural Network based dynamic modelling of indigenous pneumatic muscle actuators," in 2012 IEEE/ASME International Conference on Mechatronics and Embedded Systems and Applications (MESA), , 2012, pp. 190-195.

[8] B.-S. Kang, C. S. Kothera, B. K. Woods, and N. M. Wereley, "Dynamic modeling of Mckibben pneumatic artificial muscles for antagonistic actuation," in IEEE International Conference on Robotics and Automation, 2009. ICRA'09. , 2009, pp. 182-187.

[9] D. Trivedi, C. D. Rahn, W. M. Kier, and I. D. Walker, "Soft robotics: Biological inspiration, state of the art, and future research," Applied Bionics and Biomechanics, vol. 5, pp. 99-117, 2008.

[10] I. S. Godage and I. D. Walker, "Dual Quaternion based modal kinematics for multisection continuum arms," in 2015 IEEE International Conference on Robotics and Automation (ICRA), , 2015, pp. 1416-1422.

[11] T. Zheng, D. T. Branson III, R. Kang, M. Cianchetti, E. Guglielmino, M. Follador, et al., "Dynamic continuum arm model for use with underwater robotic manipulators inspired by octopus vulgaris," in 2012 IEEE International Conference on Robotics and Automation (ICRA), , 2012, pp. 5289-5294.

[12] H. P. H. Anh, "Online tuning gain scheduling MIMO neural PID control of the 2-axes pneumatic artificial muscle (PAM) robot arm," Expert systems with applications, vol. 37, pp. 6547-6560, 2010.

[13] S. Davis, N. Tsagarakis, J. Canderle, and D. G. Caldwell, "Enhanced modelling and performance in braided pneumatic muscle actuators," The International Journal of Robotics Research, vol. 22, pp. 213-227, 2003.

[14] T. D. C. Thanh and K. K. Ahn, "Nonlinear PID control to improve the control performance of 2 axes pneumatic artificial muscle manipulator using neural network," Mechatronics, vol. 16, pp. 577-587, 2006.

[15] B. Tondu and P. Lopez, "Modeling and control of McKibben artificial muscle robot actuators," Control Systems, IEEE, vol. 20, pp. 15-38, 2000.

[16] T. Szepe, "Accurate force function approximation for pneumatic artificial muscles," in 2011 3rd IEEE International Symposium on Logistics and Industrial Informatics (LINDI), , 2011, pp. 127-132.

[17] T. Nakamura and H. Shinohara, "Position and force control based on mathematical models of pneumatic artificial muscles reinforced by straight glass fibers," in 2007 IEEE International Conference on Robotics and Automation, , 2007, pp. 4361-4366.

[18] I. S. Godage, D. T. Branson, E. Guglielmino, and D. G. Caldwell, "Pneumatic muscle actuated continuum arms: Modelling and experimental assessment," in 2012 IEEE International Conference on Robotics and Automation (ICRA), , 2012, pp. 4980-4985.

[19] M. More and O. Líška, "Comparison of different methods for pneumatic artificial muscle control," in Proceedings of the IEEE 11th International Symposium on Applied Machine Intelligence and Informatics (SAMI2013), January31-February2, 2013, pp. 117-120.

[20] G. Andrikopoulos, G. Nikolakopoulos, and S. Manesis, "Advanced Nonlinear PID-Based Antagonistic Control for Pneumatic Muscle Actuators," IEEE Transactions on Industrial Electronics,, vol. 61, pp. 6926-6937, 2014.

[21] C.-P. Chou and B. Hannaford, "Measurement and modeling of McKibben pneumatic artificial muscles," IEEE Transactions on Robotics and Automation., vol. 12, pp. 90-102, 1996.

[22] B. Tondu, "Modelling of the McKibben artificial muscle: A review," Journal of Intelligent Material Systems and Structures, vol. 23, pp. 225-253, 2012.

[23] R. Kang, D. T. Branson, T. Zheng, E. Guglielmino, and D. G. Caldwell, "Design, modeling and control of a pneumatically actuated manipulator inspired by biological continuum structures," Bioinspiration \& biomimetics, vol. 8, p. 036008, 2013.

[24] D. Trivedi, A. Lotfi, and C. D. Rahn, "Geometrically exact models for soft robotic manipulators," Robotics, IEEE Transactions on, vol. 24, pp. 773-780, 2008.

[25] I. S. Godage, D. T. Branson, E. Guglielmino, G. A. MedranoCerda, and D. G. Caldwell, "Dynamics for biomimetic continuum arms: A modal approach," in 2011 IEEE International Conference on Robotics and Biomimetics (ROBIO), , 2011, pp. 104-109.

[26] I. S. Godage, D. T. Branson, E. Guglielmino, and D. G. Caldwell, "Pneumatic muscle actuated continuum arms: Modelling and experimental assessment," in Robotics and Automation (ICRA). 2012 IEEE International Conference on, 2012, pp. 4980-4985. 